\title{
Paraplegia
}

\section{Targeting Teenagers in a Spinal Cord Injury Prevention Program}

\author{
S. I. Weingarden, MD, ${ }^{1}$ P. M. Graham, RN, MS, CRRN ${ }^{2}$ \\ ${ }^{1}$ Project Director, ${ }^{2}$ System Co-ordinator, Southeastern Michigan Spinal Cord Injury \\ System, Rehabilitation Institute, 261 Mack Boulevard, Detroit, Michigan 48201, USA
}

\section{Summary}

The problem of teenage spinal cord injury (SCI) secondary to gunshot wounds was observed in a model SCI system. By identifying one factor, 'risk taking', in which the system could intervene, a SCI prevention program was developed that has had major community attention. Hopefully, it will also meet the needs of other communities experiencing interpersonal violence among adolescents.

Key words: Teenagers; Spinal cord injury; Gunshot wounds; Violence; Prevention program.

Despite significant advances in medical technology, traumatic spinal cord injuries (SCI) continue to be incurable, costly and catastrophic. The treatment of choice, therefore, is the proverbial 'ounce of prevention'. Prevention programs have been developed to address two major causes of SCI: motor vehicle accidents (MVAs), and diving accidents. Slogans, such as 'don't drink and drive,' 'Feet first, first time,' and 'Buckle up!' are becoming familiar to the general public.

The pattern of causation for SCI patients admitted to the Southeastern Michigan Spinal Cord Injury System (SEMSCIS) over the past 5 years, however, is significantly different. The major cause of injury has been gunshot wounds due to interpersonal violence. One hundred and twenty six persons or $38 \%$ of the total SEMSCIS population were victims of violent acts (primarily gunshot wounds or stabbing) as compared to the National Model Systems statistics of $14 \%$. Even more alarming was the fact that 36 of the SEMSCIS patients were between the ages of 13 and 19 years of age. Teenagers, therefore, were chosen as the primary target population for a SCI prevention program because they could be reached through the public school system and through other established community youth agencies. 


\section{Disease model}

The development of a prevention program for teenagers who could be potential victims of gun shootings required, first of all, an understanding of interpersonal violence. The disease model of patient or agent, host and environment as proposed by Hadden (1980) was modified in order to include injuries due to intentional shootings. The agent is the assailant; the vector is the gun; the host is the victim and the environment is the result of both social and political factors that encourage or tolerate acts of violence.

\section{The agent}

Seeman in 1959 suggested that 'an individual's alienation from society brings about feelings of powerlessness, meaninglessness, value isolation, and self estrangement.' This, he felt, was the major factor in the development of the agent. Alienation may bring about socially deviant behavior, such as shooting one's peers. Lewis, in 1984, identified some additional factors of low threshold for violence, low religiosity and low academic achievement. Thus, multiple factors may be present in the creation of the agent.

\section{The environment}

Foege in 1985 suggested that factors, such as family disintegration, unemployment, discrimination, and other psychosocial deprivations provided the milieu for violence. In addition, national societal problems of easy availability of guns, illegal drugs and 'glamorisation' of violence, intensify the environmental issues. These factors create an environment and a host with complex and multiple underlying problems beyond a SCI system's purview.

\section{Host}

Dennis (1980) found in her study of victims of violence that frequently the characteristics of agents and hosts were similar in that both may have had low educational attainment, a previous history of juvenile detention, drug involvement and gun possession.

\section{Patient population}

Of the 36 teenagers with gun related SCI, the average age was 17; 33 were male and 3 were female. Twenty three were students attending school regularly prior to their injury; 2 had completed high school and 11 were high school drop-outs (Table I). The patients were questioned about the circumstances they perceived as responsible for their shooting. Their responses included: selecting the wrong peer group, possession of a gun, drug use or sales, antagonising violent adults, attending events or places known for outbreaks of violence, wearing expensive items (gold chains), and fighting. The common denominator, however, was 'risk taking' which placed the patient in the wrong place at the wrong time (Table II). 
Table I Demographic and other characteristics of victims

\begin{tabular}{|c|c|c|c|c|c|c|c|c|c|c|}
\hline & \multicolumn{3}{|c|}{ Age } & \multicolumn{2}{|c|}{ Race } & \multicolumn{3}{|c|}{ Grade school } & \multicolumn{2}{|c|}{$\begin{array}{c}\text { Injury } \\
\text { level }\end{array}$} \\
\hline & $13-15$ & $16-17$ & $18-19$ & B & W & $6-8$ & $9-12$ & H S Grad & Quad & Para \\
\hline Male & 6 & 17 & 10 & 31 & 2 & 1 & 31 & 2 & 3 & 30 \\
\hline Female & & 3 & & 2 & 1 & & 2 & & & 3 \\
\hline Total & 6 & 20 & 10 & 33 & 3 & 1 & 33 & 2 & 3 & 33 \\
\hline
\end{tabular}

Table II Common causal pre-violence circumstances

\begin{tabular}{lrcr}
\hline & Male & Female & Total \\
\hline Arguments - fights & 11 & - & 11 \\
Assaults and robberies & 4 & 1 & 5 \\
Accidental shootings & 5 & - & 5 \\
Suicide attempts & - & 1 & 1 \\
Robbery attempts & 1 & - & 1 \\
Random shootings & 1 & 1 & 2 \\
Unknown cause & 11 & - & 11 \\
Total & 33 & 3 & 36 \\
\hline
\end{tabular}

\section{Risk taking}

Risk taking in an adolescent is not an abnormal behavior pattern. Jessor in 1984 indicated that as a child enters middle school, taking dares promoted by peers replaces ordinary games of childhood. During the high school years a feeling of self centeredness as suggested by Lewis (1984) leads to a perception of personal invulnerability despite inexperience. Thus, ignorance or disregard of consequences as a result of limited experience (Irwin and Millstein, 1984) makes risky behaviour an inevitable consequence. It was our feeling, therefore, that our patients were injured while involved in normal behaviour. What had changed, in comparison to previous years, was the consequences. Changes in the environment leading to the development of the assailant also encouraged the use of guns as evidence of masculinity or power.

\section{Prevention Program Plan}

Although our model system did not treat all the adolescent SCI victims of shootings in Southeastern Michigan, we recognised from newspaper and community reports that teenage shootings were epidemic and every shooting had the potential catastropic injury or death. The thrust of the program, therefore, was community awareness of risk taking behaviour and education of the target population about the potential consequences of shootings. Joint efforts were initiated with community agencies as well as 'grass roots' organisations because of the urgency and seriousness of the problem.

The initial phase of the program involved the distribution of 'Ban the Handgun' lapel buttons to high school students, followed by further publicity through distribution of bumper stickers. With private sponsorship, a poster contest was held for high school students using the topic of guns and SCI. Prizes were given at a public 
luncheon which generated enough interest to bring in city newspaper coverage. All teenagers involved, both victims and contestants, felt that the program increased their awareness of the problem.

The next phase of the program was bringing high school groups into the rehabilitation hospital and having our teenage patients address questions and tell their stories. As a result of the great concern in the community that teenage gun use was having, representatives from newspapers, radio, and local TV stations also attended the session. The impact on the visiting students was highly emotional and, as described by the media, 'teens speaking to teens' was seen as a powerful tool in breaking down feelings of invulnerability.

When the event was repeated with other community groups with equal impact, it was realised that a video could bring the message to a wider audience. 'Wasted Dreams,' a video, was then developed using the same format of having 5 teenage patients tell their stories. Over 100 copies of the video have been distributed nationally and as far away as Brazil. Each video is distributed with a leader's discussion guide, a student's pamphlet and a request for feedback about how the video is used. In the public schools of Philadelphia, Chicago, Los Angeles, Oakland and San Francisco, the emphasis is placed on interpersonal violence prevention. When the SEMSCIS team visits a Detroit school, however, prior knowledge about SCI victims in that school's community and indentification of the video's participants by school enables the presenter to personalise the message to the students. A brief lesson on the anatomy of the spinal cord is followed by a request for a show of hands if students know a teenager who has been shot. The students are given a brief sketch about the young people in the video and are asked to listen closely to what they have to say about the risks they took prior to their injury. After the 27 minute video is over, the discussion about risk-taking activities begins. Role playing is used to demonstrate how fights can be avoided. Boys discuss with girls how jealousness can lead to a macho-type fight.

When large audiences are expected, one of the video's young, disabled participants is asked to accompany the presenter to heighten interaction with the audience. Long term attitudinal changes directly attributable to the video were difficult to measure; however the use of a written quiz as a homework assignment has shown increased knowledge of dangers and consequences.

Developing a prevention program that targets adolescents requires an understanding of normal adolescent behaviour, subculture experiences and causal factors (Stith, 1985). Close communications with community organisations during the planning stage will assure acceptance and promotion by agencies who have a vested interest in the targeted population.

\section{References}

Dennis R 1980 Homicide Among Black Males: Social Costs to Families and Communities. Public Health Reports, November-December, 95:6, p. 556.

FOEGE W 1985 Violence and Public Health. The Surgeon General's Workshop on Violence and Public Health Report. U.S. Department of Health and Human Services Publication No. HRS-D-MC, p. 19-23.

HADDON W JR 1986 Advances in the epidemiology of injuries as a basis for public policy. Public Health Reports 95:411-421.

IRVIN C, MILLSTEIN S 1986 Biopsychosocial correlates of risk-taking behavior during adolescence. Fournal of Adolescent Health Care 7:82S-96S. 
JESSOR R, cited by LEwIS C, LEwIS MA 1984 Peer pressure and risk-taking in children. American Fournal of Public Health 74:580-584.

LEWIS C, LEWIS MA 1984 Peer pressure and risk taking in children. American fournal of Public Health 74:580-584.

Seeman M, cited by Moynihan D 1970 Maximum Feasible Misunderstanding. The Free Press, New York, p. 49-50.

STITH-PROTHROW D 1985 Interdisciplinary Intervention Applicable to Prevention of Interpersonal Violence and Homicide in Black Youth. The Surgeon General's Workshop on Violence and Public Health Report. U.S. Department of Health and Human Services Publication No. HRS-D-MC, p. $35-42$. 